\title{
As mídias sociais na prática do professor
}

\author{
Késsia Mileny de Paulo Moura ${ }^{1}$ \\ Luciele Oliveira de Carvalho ${ }^{2}$
}

\section{Resumo}

As novas tecnologias digitais modificam não só a visão de mundo de seus usuários, mas também as suas habilidades cognitivas, instaurando novas relaçóes sociais e formas de aprender. Este trabalho é sobre a utilização de mídias sociais, especificamente as redes sociais, em favor do processo de ensino-aprendizagem, e sobre como o professor se vale destas ferramentas em sua prática pedagógica. Por se constituir um espaço de interação e compartilhamento de informaçóes e conhecimentos entre diferentes usuários, as redes sociais vêm se tornando cada vez mais significativas na vida das pessoas e uma prática bastante comum na sociedade tecnológica. Partindo desses enunciados, definiu-se como objetivo geral investigar a utilização das redes sociais no processo de ensino-aprendizagem mais interativo e colaborativo. Para tanto, foram aplicados questionários com 45 alunos e realizada entrevista com uma professora de uma turma de ensino médio de uma escola particular de Imperatriz (MA). As possibilidades de ensino são multiplicadas quando se utilizam essas ferramentas digitais, e, com o estudo de caso, foi possível constatar a presença, a aceitaçáo e o potencial da utilização das redes sociais no desenvolvimento de competências nos alunos.

Palavras-chave: prática pedagógica; redes sociais; potencial interativo e colaborativo.

\section{The social media in the practice of the teacher}

\section{Abstract}

New digital technologies change not only their users' worldview, but also their cognitive skills, establishing new social relationships and ways of learning. This paper is about the use of social media, specifically social networks, in favor of the teaching-learning process and how the teacher uses these tools in his pedagogical practice. As a space for interaction and sharing of information and knowledge between different users, social networks are becoming increasingly significant in people's lives and a very common practice in the technological society. Based on these statements, it was defined as a general objective to investigate the use of social networks in the more interactive and collaborative teaching-learning process. For this, questionnaires were applied with 45 students and an interview was conducted with a teacher from a high school class of a private school in Imperatriz (MA). The teaching

1 Doutoranda no Programa de Pós-Graduação em Informática na Educação pela Universidade Federal do Rio Grande do Sul-PGIE/UFRGS. E-mail: kessiaita@gmail.com.

2 Pedagoga pela Universidade Federal do Maranhão. E-mail: luciele.de.carvalho@gmail.com. 
possibilities are multiplied when using these digital tools, and with the case study it was possible to verify the presence, acceptance and potential of the use of social networks in the development of students' skills.

Keywords: pedagogical practice; social networks; interactive and collaborative potential.

\section{Introdução}

As tecnologias impóem aos sujeitos novos modos de lidar com a informação e com o conhecimento. O contexto dinâmico e interativo em que vivemos com o advento das tecnologias desafia os docentes em sua prática pedagógica, requerendo planejamentos de situações didáticas de ensino-aprendizagem que desenvolvam novas habilidades nos alunos a partir dos recursos e ferramentas disponíveis, como celulares, computadores, e-books, blogs, fóruns virtuais, redes sociais, softwares, jogos digitais, YouTube, Google Maps.

Os professores precisam aprender a gerenciar as tecnologias digitais de informaçáo e comunicação, pois ensinar com e para o uso crítico das tecnologias é função primordial da escola. Elas vêm conquistando cada vez mais espaço na sociedade e podem ser incorporadas no ambiente educacional, assumindo assim uma importante função como mediadoras de uma aprendizagem dinâmica (KENSKI, 2012; LORENZO, 2013).

Em vez de proibir o celular em sala de aula, por exemplo, os professores podem utilizá-lo para a comunicação, a navegação, a pesquisa, a filmagem e a fotografia, desde que haja planejamento e direcionamento. Para tanto, é necessário que os docentes reflitam sobre alguns recursos que podem ser utilizados na organizaçáo de situações didáticas voltadas para a interação e o compartilhamento de informaçôes, visto que, por meio desses novos recursos, os alunos podem expandir e difundir suas linguagens e aprendizagens, além de construir novos sentidos, nos quais possam reinventar seus papéis constantemente (LORENZO, 2013; LEKA, GRINKRAUT, 2014).

Para Silva (2011, p. 31), utilização de ferramentas tecnológicas na educaçáo, principalmente as redes sociais, segue diferentes finalidades, como "divulgar e compartilhar experiências, promover maior interação entre alunos e professores, ampliar a divulgação de informaçóes, propiciar interaçôes entre leitores e escritores, além de inúmeras possibilidades que podem ser associadas às demandas de aprendizagem dos educandos", que, por sua vez, revelam-se como aspecto importante a ser desenvolvido no contexto educativo. 
Partindo disso, buscamos investigar a utilização de redes sociais como recurso potencializador de interação e colaboração na troca de informaçôes e conhecimentos necessária ao processo ensino-aprendizagem. A escolha desse tema, a princípio, se deu pela utilização de uma rede social onde os integrantes têm a oportunidade de trocar ideias sobre o livro do mês e sobre outras obras literárias e, até mesmo, tratar de assuntos diversos, que vão desde faculdade, escola, séries, política etc.

A partir daí surgiu o interesse sobre essa relação dos jovens com as tecnologias, se haveria a possibilidade de utilizá-las como um recurso no seu processo de aprendizagem. Paralelamente, por nosso trabalho na docência, alguns questionamentos a respeito da utilização dessas ferramentas em sala de aula foram se manifestando, principalmente sobre como as Tecnologias de Informação e Comunicação (TIC) poderiam ser utilizadas pelos professores, fazendo com que eles repensassem suas práticas pedagógicas na mediação com os livros, ou até mesmo em outras práticas de escrita. De acordo com Moran (2007), as tecnologias não substituirão os professores, mas irão permitir que várias de suas tarefas e funções possam ser transformadas, objetivando o pleno desenvolvimento do educando como parte principal no processo ensino-aprendizagem.

De natureza exploratória, esta pesquisa teve a preocupação com coletar e dar atenção a um maior número de elementos, a fim de obter uma compreensão mais apurada do problema em estudo. Os sujeitos desta pesquisa foram 45 alunos e uma professora de uma turma de $2^{\circ}$ ano do ensino médio de uma escola particular, na cidade de Imperatriz, no Estado do Maranhão. A opção por esses sujeitos da pesquisa justificou-se por, neste nível de ensino, os jovens terem mais acesso às tecnologias; ao mesmo tempo, tanto o aluno quanto o professor são capazes de construir em conjunto seus conhecimentos e suas experiências, objetivando uma possível melhoria na prática pedagógica e na aprendizagem.

O tipo de pesquisa escolhida foi o estudo de caso, que consiste em analisar detalhadamente um contexto específico, a fim de captar a realidade no decorrer da pesquisa. O estudo de caso dá oportunidade para que um aspecto de um problema seja estudado com profundidade; neste caso, o tipo de pesquisa em questáo tem por objetivo analisar os usos de redes sociais no processo de ensino-aprendizagem. $\mathrm{O}$ aspecto diferenciador do estudo de caso "reside em sua capacidade de lidar com uma ampla variedade de evidências - documentos, artefatos, entrevistas” (YIN, 2001, p. 27). 
Os instrumentos escolhidos para a coleta de dados foram um questionário aplicado com alunos e uma entrevista com a professora da turma. A respeito do questionário, Marconi e Lakatos (2003, p. 201) o definem como sendo "um instrumento de coleta de dados, constituído por uma série ordenada de perguntas, que devem ser respondidas por escrito e sem a presença do entrevistador". A importância dos questionários passa também pela facilidade com que se interroga um elevado número de pessoas, em um espaço de tempo relativamente curto, além do fato de proporcionar resultados bastante críticos e subjetivos, já que cada item pode ter respostas e significados diferentes para cada sujeito pesquisado.

Como citado anteriormente, com o professor, utilizou-se a entrevista como instrumento de coleta de dados. Segundo Lakatos e Marconi (2008, p. 278), a entrevista é "uma conversação efetuada face a face, de maneira metódica, que pode proporcionar resultados satisfatórios e informaçóes necessárias". A entrevista tem por objetivo compreender as perspectivas e as vivências dos participantes. Esse instrumento de coleta de dados, segundo Gil (1999, p. 117), seria "uma forma de interação social".

\section{Em busca de conexóes}

As diferentes tecnologias digitais tornaram-se algo imprescindível em nossa sociedade, contribuindo em diferentes modos de organizaçáo, distribuição e veiculação dos conhecimentos. A internet deu vida ao computador ao possibilitar o surgimento de diversificadas formas de práticas sociais de comunicação, aproximando virtualmente as pessoas, de maneiras até bem pouco tempo praticamente impossíveis. Para Postman (1994, p. 29), "essas novas tecnologias alteram a estrutura de nossos interesses: as coisas sobre as quais pensamos. Alteram o caráter de nossos símbolos: as coisas com que pensamos. E alteram a natureza da comunidade: a arena na qual os pensamentos se desenvolvem".

As tecnologias modificam não só a visão e modos de atuaçáo no mundo de seus usuários, mas também as suas habilidades cognitivas (LÉVY, 2001), instaurando novas relaçóes sociais e aprendizagem. Para Veen e Vrakking (2009), temos uma geraçáo que assumiu a tecnologia como meio importante de viver e aprender, desvelando o mundo através da multiplicidade de ferramentas digitais e suas implicaçóes de uso para a aprendizagem. 
Trata-se de uma geração que valoriza o compartilhamento de informaçóes e, para isso, utiliza mídias e redes sociais nas conexóes que estabelecem. Segundo Amorim et al. (2016, p. 100), os sujeitos contemporâneos nascidos no contexto da cibercultura aprendem explorando esse mundo, sem ler manuais, vão experimentando, tentando, compartilhando, recusam a passividade na espera das informaçóes e conhecimento. Eles "vão atrás da informação em um mundo on-line e virtual, através da pesquisa e nas redes sociais".

É disso que trata Kenski (2012, p. 46) quando diz que não nos restam dúvidas de que as tecnologias trouxeram mudanças na educação. Segundo ela,

transformam a realidade da aula tradicional, dinamizam o espaço de ensino-aprendizagem, onde, anteriormente, predominava a lousa, o giz, o livro e a voz do professor. Para que as TIC possam trazer alteraçóes no processo educativo, no entanto, elas precisam ser compreendidas e incorporadas pedagogicamente. Isso significa que é preciso respeitar as especificidades do ensino e da própria tecnologia para poder garantir que o seu uso realmente faça diferença. Não basta usar a televisão ou o computador, é preciso saber usar de forma pedagogicamente correta a tecnologia escolhida.

As mídias sociais virtuais se constituem como espaço de interação e compartilhamento de informaçôes entre diferentes usuários, e vêm se tornando, cada vez mais, significativas na vida das pessoas, sendo a participação nelas uma prática bastante comum na sociedade tecnológica. Aqui, o termo mídia social é utilizado para classificar ferramentas digitais que permitem a relação, criação e a troca de conteúdo gerado pelo utilizador, mas sem desconsiderar quem os manipula. Entre elas estão Facebook, WhatsApp, Instagram, Twitter, Skoob, blogs, YouTube, dentre outras. Essas podem ser acessadas por qualquer pessoa por meio de celular ou computador, o que diminui a distância entre a rede e o usuário, melhorando a transmissão de informação e comunicação entre eles.

Tratando especificamente de redes sociais, seu conceito surgiu na sociologia como um conjunto de dois elementos: atores (pessoas, instituiçóes ou grupos) e suas conexôes. Portanto,

as redes sociais, desse modo, não são pré-construídas pelas ferramentas, e, sim, apropriadas pelos atores sociais que lhes conferem sentido e que as adaptam para suas práticas sociais. [...] (S)áo percebidas como 
representações onde a interação entre os indivíduos são apontadas como representativas também das conexóes entre estes. (RECUERO, 2012, p. 20-28).

Nesse mesmo sentido, Alex Primo (2007, p. 5) destaca o aspecto da interação para caracterizar essa ferramenta, dizendo que "uma rede social não se forma pela simples conexáo de terminais. Trata-se de um processo emergente que mantém sua existência através da interação entre os envolvidos".

Nos estudos de Lorenzo (2013, p. 20) encontra-se a defesa da rede social como uma maneira de representar relacionamentos pessoais, sejam afetivos ou profissionais. É um novo canal de comunicação entre os sujeitos, que estreita laços e interaçóes, sendo responsável pelo compartilhamento de interesses, ideias e informações.

Recuero (2009) reconhece cinco aspectos que desvelam a importância das redes no contexto relacional dos sujeitos contemporâneos. Para a autora, as redes são sobre as pessoas conectadas virtualmente e não estão distantes das relaçóes estabelecidas no mundo físico. $\mathrm{Na}$ verdade, elas as mantêm e ampliam; são construídas pelas apropriaçóes que os sujeitos realizam nas relações e comunicações estabelecidas; são veículo para a informação surgir e se propagar; são espaços de conversação entre as pessoas; e, por último, são potenciais espaços de mobilização social.

Todas essas características expressam e complexificam as redes sociais. No meio educacional, por exemplo, podem ser utilizadas com diversas finalidades, como divulgar e compartilhar experiências, promover maior interação entre alunos e professores, ampliar a divulgação de informaçóes, além de inúmeras possibilidades que podem ser associadas às demandas de aprendizagem dos educandos (LEKA; GRINKRAUT, 2013).

A escola pode aproveitar o fascínio de seus alunos diante das redes sociais ao desenvolver projetos didáticos, considerando vários temas importantes que desafiam os educandos em tempos de turbilhão digital, consequentemente, facilitando também a aquisição e a ampliação de conhecimentos que podem ser usados pelos professores como recursos pedagógicos. Nesse contexto, Silva (2010, p. 41) coloca que as redes sociais, permitem

centralizar em um único local todas as atividades docente, professores e alunos de um centro educativo, aumenta o sentimento de comunidade educativa, melhora o ambiente de trabalho ao permitir que o aluno possa criar seus próprios objetos de interesse, aumenta a comunicaçáo 
entre professores e alunos e facilita a coordenação do trabalho de diversos grupos de aprendizagem (HARO, 2008a) O professor também se beneficia das redes sociais, pois pode compartilhar suas descobertas, incertezas e reflexôes com outros professores, criando um círculo contínuo de aprendizado.

Com relação a esses usos que os professores podem promover, Kenski (2012, p. 47) destaca que "as redes de comunicação trazem novas e diferenciadas possibilidades para que as pessoas possam se relacionar com os conhecimentos e aprender". As redes sociais podem representar um enorme avanço no âmbito pedagógico por possibilitar o estudo em grupo, a troca de conhecimentos e aprendizagens colaborativas, desenvolvendo assim habilidades construtivas nos alunos, e permitindo uma maior flexibilidade em estudar um conteúdo em outro momento além daquele que foi dado pelo professor.

Nesse sentido, concordamos com Silva (2010, p. 43) quando afirma ser necessária a participação ativa dos professores (no sentido de incorporarem as tecnologias digitais em suas atividades educativas) e ainda que as instituiçóes se adequem "à sociedade do conhecimento, que estimula o aprendizado permanente, a participação e colaboraçáo do aluno no seu próprio aprendizado".

Entre as redes sociais mais conhecidas, está o Facebook. O espaço virtual do Facebook pode ser apropriado como uma forma de reinvenção, reconstrução e extensão da sala de aula. Segundo Recuero (2012, p. 171), o Facebook

foi um sistema criado pelo americano Mark Zuckerberg enquanto esse era aluno de Harvard. A ideia era focar em alunos que estavam saindo do secundário (High School, nos Estados Unidos) e aqueles que estavam entrando na universidade. Lançado em 2004, o Facebook é hoje um dos sistemas com maior base de usuários no mundo.

A princípio o foco da rede social era a possibilidade dos jovens estudantes de compartilhar experiências e informaçóes pessoais e a respeito da universidade, estimulando assim a interação entre eles. Seu surgimento no ambiente acadêmico, no entanto, possibilitou pensar na sua utilização com fins pedagógicos, onde, dentre outras possibilidades, os professores poderiam organizar eventos, expor os conteúdos produzidos em sala de aula, trocar recados com a turma etc. Essa ampliação da escola no espaço virtual do Facebook abre inúmeras possibilidades de trabalho para reinventar a sala 
de aula. Mas, para usufruir da rede social com sucesso, é necessário que os sujeitos a explorem para conhecê-la melhor, para assim deleitar-se com todas as possibilidades de leitura, escrita e interação que essa rede possa oferecer.

Outro recurso muito utilizado é o WhatsApp, que tem uma função múltipla de enviar mensagens de textos, imagens, áudios e vídeos, e também arquivos de vários tipos, como PDF. Além dessas utilidades citadas, o aplicativo também tem a opção de criar grupos com a intenção de estender o diálogo com mais pessoas. O WhatsApp é bastante acessível a uma boa parte dos alunos e já é uma realidade em vários ambientes educativos como uma ferramenta facilitadora no processo de comunicação aluno-professor e aluno-aluno, além de gerar uma maior integração na turma ao criar um cenário propício para debates acerca de determinados temas intrínsecos ao contexto das disciplinas.

Os blogs constituem outro recurso também discutido entre os pesquisadores da área de tecnologias e educação, sendo ferramentas interessantes para a aprendizagem interativa e colaborativa graças às várias funcionalidades que lhes podem ser atribuídas.

É possivel formar redes descentralizadas para incentivar a interaçâo; trabalhar com imagens (fator que modifica o conceito de comunicação); navegar por textos da web; utilizar animaçáo para simplificar atividades complicadas e propiciar aos estudantes o sentimento de autores de seus trabalhos, uma vez que tudo pode ser publicado e exibido na net. (ROJO; MOURA, 2012, p. 40).

Se utilizados em sala de aula, os blogs funcionariam como diários virtuais, de caráter público, com várias informaçóes que podem ser de cunho pessoal, informativo ou educativo, e que são disponibilizadas para qualquer internauta que tenha acesso ao ciberespaço. A respeito dos blogs voltados para a área da educação, Silva e Albuquerque (2009) elencam cinco categorias de blogs educacionais: blogs de professores, utilizado para publicar orientaçóes, textos, vídeos, imagens, animaçôes, referências bibliográficas ou links; blogs de alunos, que funcionam como portfólios, reunindo suas produçóes que são utilizados pelos professores como instrumentos de avaliação; blogs de instituiçóes educativas, voltados à divulgação do trabalho desenvolvido e à autopromoção; blogs de projetos educativos, destinados à produção e socialização de conhecimentos sobre temas específicos; e blogs de grupos de pesquisa, que são como "colégios invisíveis", reunindo pessoas de comu- 
nidades científicas diversas para interlocução, articulação de suas pesquisas, divulgação, análise de resultados e avaliação de textos.

Em todos os exemplos destaca-se a principal vantagem do blog: o incentivo à interação e a colaboração entre seus usuários, e ele pode ser utilizado tanto como recurso quanto como estratégia pedagógica. Gomes (2011) destaca que como recurso pedagógico os blogs podem ser um espaço de acesso à informação especializada, um espaço de disponibilização de informação por parte do professor. Como estratégia pedagógica, podem assumir a forma de um portfólio digital, um espaço de intercâmbio e colaboração, de debate e de integração. A ferramenta permite constante troca de informaçóes e construção mais colaborativa, proporcionando produção, reprodução e difusão de conhecimentos.

O professor precisa saber utilizar essas ferramentas de maneira apropriada (LORENZO, 2013), para que ocorra o bom desempenho e eficácia de seu trabalho, exigindo também que ele planeje as atividades, e que sejam bem dirigidas, para que não haja essa dispersão, pois "cada momento da situação de aprendizagem requer uma estratégia diferente conforme o momento" (Coscarelli; Ribeiro, 2005, p. 27).

Portanto, as tecnologias da informação e comunicação estão exigindo professores e alunos mais interativos e colaborativos. A introdução dessa cultura digital pode enriquecer ainda mais os ambientes escolares, ao possibilitar novas formas de ver o mundo e aprender no mundo, de produzir, interagir e comunicar (LORENZO, 2013; SILVA, 2010).

\section{Recursos, sujeitos, conexóes}

A escolha pela escola deu-se principalmente pelo histórico de utilização das TIC em sala de aula e fora dela, por meio de feiras científicas e robóticas, e por oferecer uma estrutura bem equipada aos alunos e professores. Possui sala de informática, constituída por 25 computadores, todos com acesso a internet, que é utilizada para diversas atividades, como pesquisas escolares direcionadas e aulas mais específicas, como no caso de robótica, oferecida pela escola.

Lembramos que, nesta pesquisa, foi destacada a utilização das redes sociais como um recurso pedagógico que fomentasse a interação e colaboração. Assim, primeiro questionamos os alunos se eles acreditavam no uso 
dessas redes sociais, como o Facebook e o Whatsapp, como uma ferramenta favorável nas aulas (gráficos 1 e 2).

Gráfico 1 - Utilização do Facebook como ferramenta favorável nas aulas

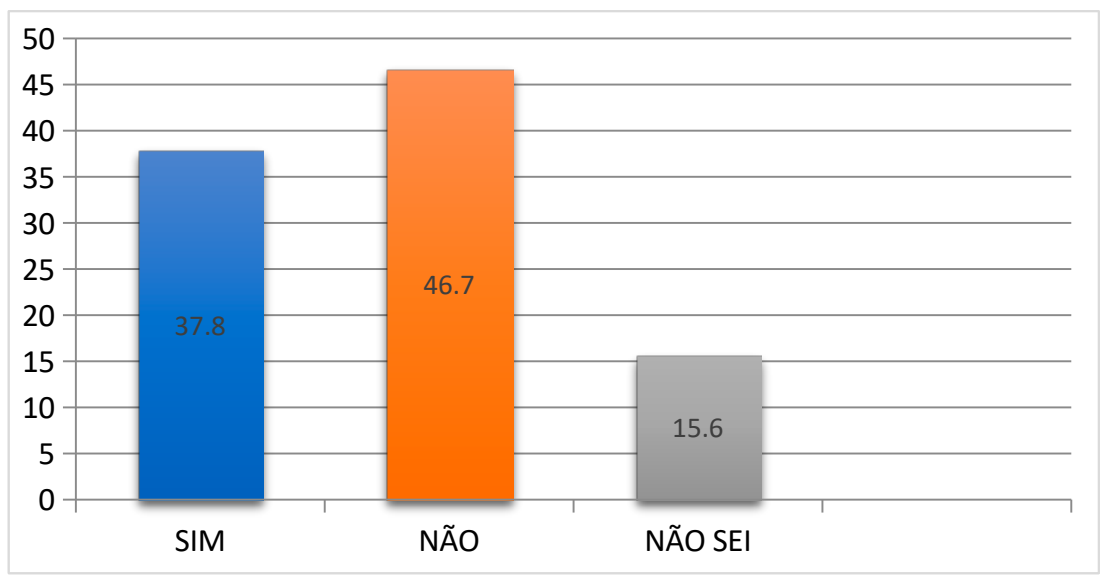

Fonte: Dados da pesquisa.

Entre as redes sociais, o Facebook é uma das mais utilizadas em todo o mundo. Porém, para $46,7 \%$ dos participantes da pesquisa, esta mídia não carrega fator favorável para processo educativo. Sobre esse dado, apresentado na fig. 1, pode-se inferir duas questóes. Primeiro, essa rede social tem sido utilizada para estabelecer vínculos e relaçôes entre pessoas, divulgar e compartilhar informaçóes pessoais das mais diversas ordens. Parece que essa conotaçáo ancorada em interaçóes e relacionamentos virtuais extraescolares seja um forte motivo para os sujeitos a encararem como prática social distante dos cânones que o processo educativo convenciona. Talvez os alunos concebam estudo e participação nas redes sociais em polos diferentes, e mais, não consigam articular essa ferramenta em função de sua aprendizagem.

Isso nos remete à segunda observação: a necessidade da devida articulação das redes sociais nos processos educativos pela prática do professor (LORENZO, 2013). Lembrando Kenski (2012, p. 46), para que as tecnologias possam provocar alteraçóes no processo educativo, "elas precisam ser compreendidas e incorporadas pedagogicamente. Isso significa que é preciso respeitar as especificidades do ensino e da própria tecnologia para poder garantir que o seu uso realmente faça diferença”. 
Quando fomentada essa articulação, poderia promover a superação dessa polarização e tornar o processo ensino-aprendizagem mais próximo das práticas cotidianas do aluno, além de ampliar o repertório de ferramentas possíveis a esse processo e o espaço educativo para além da escola, como nos coloca Recuero (2012).

Já em relação à utilização do WhatsApp, a maioria dos sujeitos participantes aponta uma percepção diferente, como vemos na fig. 2 .

Gráfico 2 - Utilização do WhatsApp como ferramenta favorável nas aulas

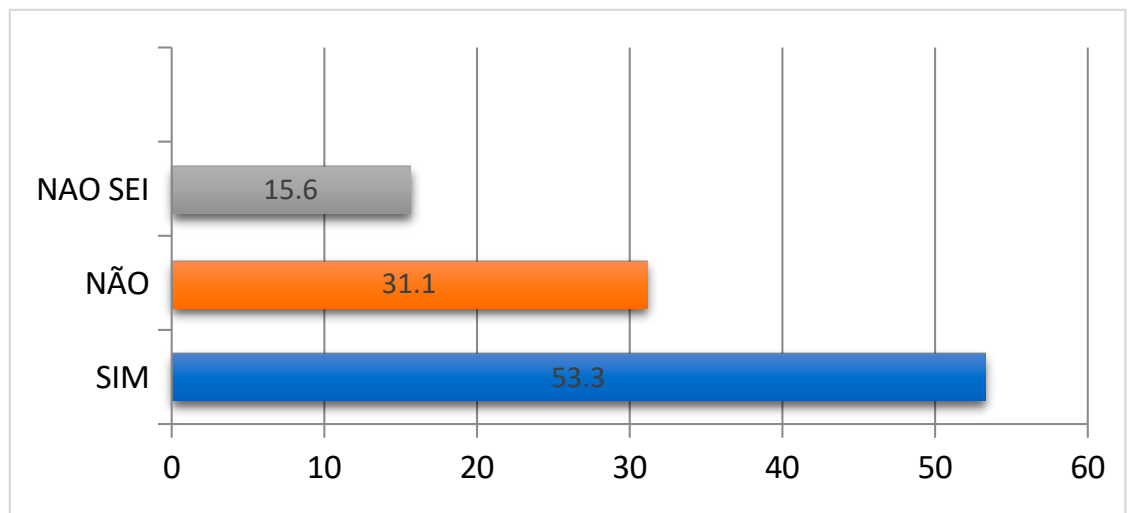

Fonte: Dados da pesquisa.

Percebe-se que mais de $53 \%$ dos alunos acreditam que pode haver, sim, a utilização dessa rede social como uma forma ou fonte de aprendizagem. A utilização de grupos no WhatsApp, por exemplo, permite que todos os alunos da sala que tenham esse aplicativo participem de um grupo que pode ser usado para tirar dúvidas com os outros alunos, informar aos que faltaram alguma atividade que os professores passaram naquele dia, ou compartilhar textos, slides ou outros arquivos que o professor possa ter disponibilizado. Grupos menores podem ser criados, por exemplo, para um trabalho em equipe, pois permitem troca de informaçóes mais rápida e acessível aos integrantes que vivem em bairros distantes.

Esse antagonismo nos dados que representam a utilização do Facebook e do WhatsApp nos chama atenção. Parece-nos que essa maior aceitação do WhatsApp para os alunos ocorre pela facilidade de comunicação e acesso que essa mídia social oferece, deixando as pessoas mais livres para interagir, compartilhar e até mesmo ampliar a sua capacidade de reflexão. 
Kenski (2012, p. 66) se refere aos recursos tecnológicos de informação e comunicação "e o ciberespaço como um novo espaço pedagógico que oferece grandes possibilidades e desafios para a atividade cognitiva, afetiva e social". Sua utilização, quando adequada, estimula os alunos e professores a desenvolverem maior senso crítico na busca de conteúdos e outras competências. A autora afirma que

o compartilhamento de informaçóes e as múltiplas possibilidades de comunicação e interação imediatas garantem que escolas, universidades, instituiçôes educacionais e culturais, empresas e organizaçóes de todo o mundo possam produzir e utilizar cooperativamente conhecimentos, produtos, serviços e conteúdos nas mais diferenciadas áreas científicas. (KENSKI, 2012, p. 91).

Contudo, pareceu-nos predominar nesse uso do WhatsApp como ferramenta educativa uma articulação dos próprios alunos, servindo como um espaço interativo e colaborativo para esclarecimentos e trocas de informações, por isso, já sendo mais aceito na turma, ou melhor, já sendo uma prática consolidada. Esse fato é bastante pertinente, pois releva que mídias digitais já fazem parte das práticas escolares concretas deles, já estão introduzidas nas maneiras de estudar e aprender desses sujeitos (Silva, 2011). Nas figuras 1 e 2, trazemos diálogos entre alunos da turma pesquisada que ratificam essa argumentação em que a interação e colaboração ocorrem. 
Fig. 1 - Grupo de WhatsApp da disciplina

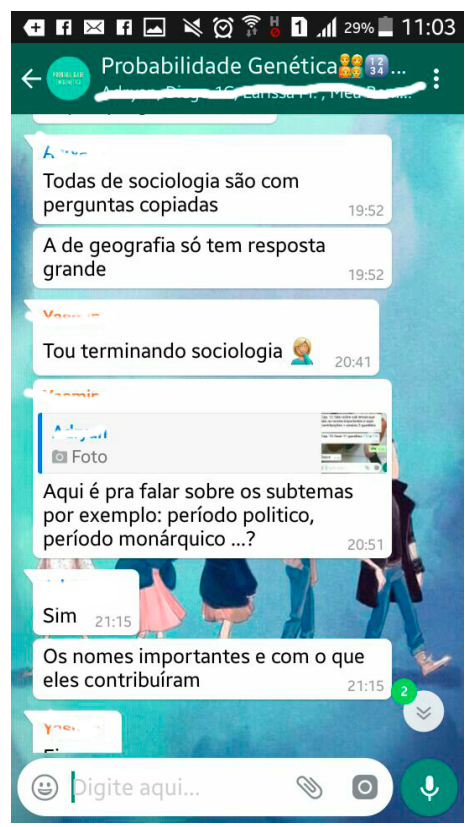

Fonte: Dados da pesquisa.
Fig. 2 - Grupo de WhatsApp da disciplina

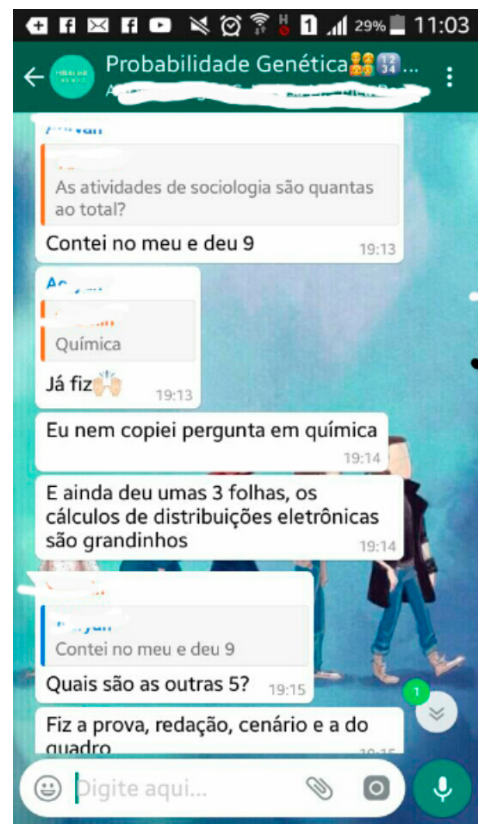

Fonte: Dados da pesquisa.

Porém, esse mesmo dado reclama também articulação e mediação do professor, como já destacamos acima. Os professores precisam dispor de métodos interativos e socializadores para estimular uma aprendizagem significativa e romper com os mais tradicionais (MORAN, 2012; LORENZO, 2013). Como lembram Coscarelli e Ribeiro (2005), cada momento de aprendizagem requer outros expedientes do professor, e este momento contemporâneo solicita práticas mais dinâmicas e situadas no contexto tecnológico.

Pensando nisso, perguntou-se à professora sobre a utilização de mídias e redes sociais, que afirmou ser possível, sim, trabalhar por meio das mídias sociais, e que é a utilização feita pelos usuários que traz sentido educativo e melhor aproveitamento às tecnologias.

Professora - Sim. Adapto as mídias às aulas e as aulas aos recursos disponíveis, de acordo com a necessidade do objetivo a ser alcançado, a disciplina e aos alunos, para que haja uma melhor absorção, 
entendimento e compreensão. Assim, alunos e professores se adequam ao mundo digital, tirando proveito desse recurso que conquista os alunos.

O uso de recursos nas escolas traz inúmeras possibilidades e mudanças significativas para o processo de ensino-aprendizagem, e, a cada momento, nos deparamos com as enormes utilidades que a internet oferece para $o$ processo; em um leque de possibilidades que concebe ao aluno diferentes experiências e aprendizagens, fazendo-o interagir com diferentes formas de textos, imagens, sons, relaçóes interpessoais e outras competências. Para Lorenzo (2013, p. 94), "o educador é um profissional que necessita conhecer as possibilidades e a importância agregada ao método de ensino e aprendizagem que as redes de relacionamento propiciam”.

Ainda segundo Lorenzo (2013, p. 30), além de se efetivar como espaço de colaboração no processo educativo e servir para construir e compartilhar materiais, com as redes sociais,

o professor por sua vez terá a oportunidade de verificar aspectos muitas vezes difíceis de serem identificados em uma sala de aula, como a capacidade de elaborar textos, melhoria do desenvolvimento na escrita, a pesquisa sobre um assunto, a apresentação de uma opinião e o debate entre os alunos.

Nesse sentido, concordamos com Kenski (2012, p. 73), ao argumentar que a utilização de ferramentas tecnológicas digitais remete à assunção de uma nova postura filosófica de ensino-aprendizagem, que contempla visóes inovadoras que aproveitem as "amplas possibilidades comunicativas e informativas das novas tecnologias, para a concretização de um ensino crítico e transformador de qualidade".

Consultamos ainda os alunos a respeito das ferramentas utilizadas pela professora para o compartilhamento e produção de materiais educativos. Para 35\% dos alunos, a professora utiliza mídias como recurso principal na produção e compartilhamento desses materiais. Vejamos no gráfico 3 os percentuais das mídias utilizadas, baseados nas declaraçóes dos alunos. 
Gráfico 3 - O professor utiliza algum recurso midiático para compartilhar ou produzir materiais educativos?

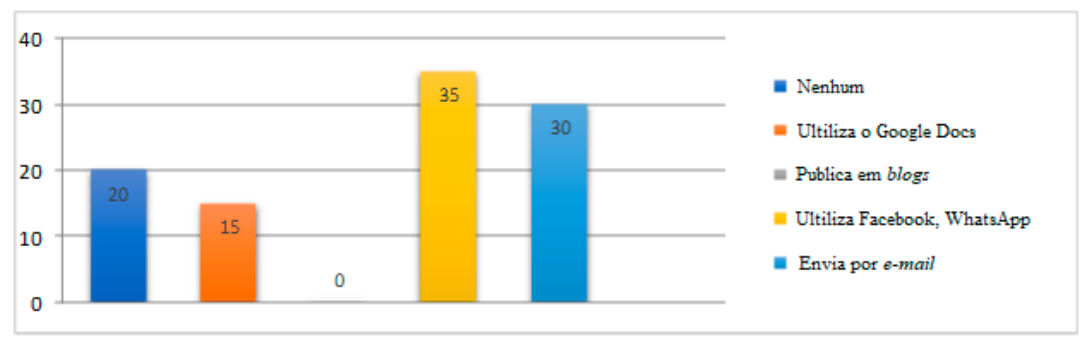

Fonte: Dados da pesquisa.

Ao analisar o gráfico, percebe-se que a professora tem buscado abrir novas formas de trocar experiências e conhecimentos, disponibilizando por meio dessas mídias sociais, informaçóes, conteúdo das aulas ministradas, materiais de apoio e exercícios complementares, estabelecendo assim um contato para além da sala de aula. De acordo com Kenski (2012), as redes de comunicaçáo favorecem novas e diferenciadas possibilidades de relacionamentos e construção de conhecimentos, criam espaços mais dinâmicos com atividades mais interativas e colaborativas, proporcionando a alunos e professores novas maneiras de ensinar a aprender, pensar e agir.

Nessa perspectiva, concordamos com Moran (2004, p. 10) quando destaca que podemos "aprender estando juntos fisicamente e também conectados, podemos aprender no mesmo tempo e ritmo ou em tempos, ritmos e formas diferentes". Portanto, o trabalho do professor com as tecnologias vai além da sala de aula, no qual o mundo físico e o virtual não se opóem, mas se completam, tendo como finalidade principal beneficiar o processo de ensino-aprendizagem.

\section{Consideraçóes finais}

Inserir as mídias nas práticas docentes significa modificar as maneiras de ensinar e aprender postas atualmente. Nesse sentido, concordamos com Moran (2004, p. 63), que afirma que "ensinar com as novas mídias será uma revolução se mudarmos simultaneamente os paradigmas convencionais do ensino, que mantêm distantes professores e alunos. Caso contrário, conseguiremos dar um verniz de modernidade, sem mexer no essencial”. 
As possibilidades de ensino são multiplicadas quando se utilizam essas ferramentas digitais, pois a utilização dos "diferentes meios para aprender a se relacionar com a inovação e ir além, começar a criar novas formas de uso e, daí gerar outras utilizaçóes" (KENSKI, 2012, p. 44).

Para Lorenzo (2013, p. 35), "o desafio para os educadores é a incorporação dos recursos da internet em redes sociais com uma finalidade de beneficiar o processo de ensino e aprendizagem". Como foi identificado pela pesquisa, professora e alunos se mostraram abertos e receptivos quanto ao uso das redes sociais como recurso. Foi possível compreender a importância de se trabalhar com as mídias sociais, mais especificamente as redes sociais. A construção e compartilhamento de conhecimentos com o suporte das redes sociais pôde contribuir para que os alunos se interessassem cada vez mais pelas aulas, facilitando seu entendimento, promovendo maior interação, participação, colaboraçáo.

\section{Referências}

AMORIM, M. C. M. et al. Aprendizagem e Jogos: diálogo com alunos do ensino médio-técnico. Educação \& Realidade, Porto Alegre, v. 41, n. 1, p. 91-115, jan./mar. 2016. Disponível em: http://www.scielo.br/scielo. php?pid=S2175-62362016000100091\&script=sci_abstract \&tlng=pt. Acesso em: 23 nov. 2018.

COSCARELLI, C. V.; RIBEIRO, A. E. Letramento Digital: aspectos sociais e possibilidades pedagógicas. Belo Horizonte: Ceale, Autêntica, 2005.

GIL, A. C. Métodos e técnicas de pesquisa social. 5. ed. São Paulo: Atlas, 1999.

GOMES, L. F. Hipertexto no cotidiano escolar. São Paulo: Cortez, 2011.

KENSKI, V. M. Educação e tecnologias: o novo ritmo da informação. 8. ed. Campinas: Papirus, 2012.

LAKATOS, E. M.; MARCONI, M. A. Técnicas de pesquisa: planejamento e execução de pesquisas, amostragens e técnicas de pesquisa, elaboração, análise e interpretação de dados. 7. ed. São Paulo: Atlas, 2008.

LEKA, A. R; GRINKRAUT, M. L. A utilização das redes sociais na educação superior. Revista Primus Vitam, no 7, 2014. Disponível em: http://delphosgp.com/primus_vitam/primus_7/aline.pdf. Acesso em: 14 dez. 2018. 
LÉVY, P. Cibercultura. São Paulo: Editora 34, 2001.

LORENZO, E. M. A Utilização das Redes Sociais na Educação: $A$ Importância das Redes Sociais na Educação. 3. ed. São Paulo: Clube de Autores, 2013.

MARCONI, M. A.; LAKATOS, E. M. Fundamentos de metodologia científica. 5. ed. São Paulo: Atlas, 2003.

MORAN, J. M. A Educação que Desejamos: Novos desafios e como chegar lá. 5. ed. Campinas, SP: Papirus, 2012.

MORAN, J. M. Desafios na Comunicação Pessoal. São Paulo: Paulinas, 2007.

MORAN, J. M. Os novos espaços de atuação do professor com as tecnologias. Revista Diálogo Educacional, Curitiba, v. 4, n. 12, p. 13-21, maio/ago. 2004. Quadrimestral. Disponível em: http://www.pucrs.br/ ciencias/viali/tic_literatura/artigos/tic_professores/189117821002.pdf. Acesso em: 20 nov. 2017.

POSTMAN, N. Tecnopólio. São Paulo: Nobel, 1994.

PRIMO, A. O aspecto relacional das interações na Web 2.0. In: E-Compôs, Brasília, v. 9, p. 1-21, 2007. Disponível em: http://www.ufrgs.br/limc/ PDFs/web2.pdf. Acesso em: 13 dez. 2018.

ROJO, R.; MOURA, E. Multiletramentos na escola. São Paulo: Parábola, 2012.

RECUERO, R. A conversação em rede: comunicação mediada pelo computador e redes sociais da Internet. Porto Alegre: Sulina, 2012.

RECUERO, Raquel. Cinco pontos sobre redes sociais na Internet, 2009. Disponível em: http://www.ichca.ufal.br/graduacao/biblioteconomia/v1/ wp-content/uploads/redessociaisnainternetrecuero.pdf. Acesso em: $20 \mathrm{dez}$. 2018.

SILVA, L. T.; ALBUQUERQUE, M. Blogs pedagógicos: possibilidades de interação por meio da escrita coletiva de hipertextos cooperativos. Revista Latinoamericana de Tecnología Educativa - RELATEC, v. 8, n. 2, p. 91-108, 2009. Disponível em: http://campusvirtual.unex.es/cala/editio/. Acesso em: 20 nov. 2017. 
SILVA, I. M. Tecnologias e letramento digital: navegando rumo aos desafios. ETD - Educação Temática Digital, v. 13, n. 1, p. 27-43, 30 ago. 2011. Disponível em: https://periodicos.sbu.unicamp.br/ojs/index.php/ etd/article/view/1164. Acesso em: 13 dez. 2017.

VEEN, W.; VRAKKING, B. Homo Zappiens: educando na era digital. Porto Alegre: Artmed, 2009.

YIN, R. K. Estudo de caso: planejamento e métodos. Porto Alegre: Bookan, 2001.

Recebido em: 23 ago. 2019.

Aceito em: 11 nov. 2019. 